\title{
Fetal outcome in repeat cervical encirclage in same pregnancy
}

\author{
Nirmala Sharma*, Kana Ram, Anand Sharma
}

Department of Obstetrics and Gynecology, Govt. Medical College, Kota, Rajasthan, India

Received: 14 October 2013

Accepted: 27 October 2013

\author{
*Correspondence: \\ Dr. Nirmala Sharma, \\ E-mail: nirmala_gynae@yahoo.co.in
}

(C) 2013 Sharma $\mathrm{N}$ et al. This is an open-access article distributed under the terms of the Creative Commons Attribution Non-Commercial License, which permits unrestricted non-commercial use, distribution, and reproduction in any medium, provided the original work is properly cited.

\begin{abstract}
A 30 year old sixth gravida patient having five spontaneous abortions between fifth and sixth months of amenorrhea. Patient had an incompetent cervix, cervical cerclage was done at 14 weeks of gestation by Mc Donald's method. Pregnancy was uneventful for more than one month and patient reported back with complaints of bleeding per vaginum, and pain abdomen, cerclage was removed by duty doctor in emergency, but pains subsided. Ultrasound was done revealing low lying placenta reaching upto the os with 22 weeks live intrauterine pregnancy. Repeat transvaginal cervical cerclage was decided and done in similar manner. Patient was kept indoor on bed rest, tocolytics, antibiotics and progesterone support till the time of delivery. At 30 weeks pregnancy ultrasound revealed low amniotic fluid index (1.2) for which amino acid infusion was administered. Later on patient developed bleeding \& leaking per vaginum with cervical dilatation, so immediate cesarean section decided and corticosteroid administered for fetal lung maturity, emergency cesarean section was done. In follow up mother and baby were absolutely healthy. The pregnancy outcome is significantly improved even after repeat cervical cerclage in same pregnancy and if there is a need for repeat cervical cerclage during same pregnancy it should be done to improve fetal salvage.
\end{abstract}

Keywords: Recurrent mid-trimester miscarriage, Preterm delivery, Mc Donald cerclage

\section{INTRODUCTION}

Death of an infant in utero or at birth has always been a devastating experience for the mother and of concern in clinical practice. ${ }^{1}$ Recurrent miscarriage and preterm births appear to have similar etiologies, which include cervical weakness and/or ascending infection. ${ }^{2}$ Cervical incompetence is primarily a retrospective clinical diagnosis characterized by recurrent painless dilation and spontaneous mid-trimester abortions.

\section{CASE REPORT}

A 30 year old sixth gravida was admitted in our hospital at 13 weeks 5 days on 29.2.12 with history of five spontaneous abortions between fifth and sixth months of amenorrhea. She had undergone all investigations which are within normal limits including normal thyroid profile, negative anticardiolipin antibody. Her ultrasound showed incompetent cervix of $22.6 \mathrm{~mm}$ length with no congenital malformation and her cervical encerclage was decided and done at 13 weeks 6 days on 1.3.12 by Mc Donald's method.

Her postoperative period was uneventful and she was kept on bed rest, tocolytics, antibiotics and progesterone support. She was discharged on 3.3.12 with explained prognosis and advice for proper follow up. Patient carried pregnancy uneventfully for more than one month after cerclage and reported back on 13.4.12 with complaints of bleeding per vaginum, and pain abdomen, patient was readmitted and treated conservatively (bed rest, tocolytics, antibiotics and progesterone support) but pains persisted off and on. Patient complained of strong pains on 3.5.12 and cerclage was removed by duty doctor in emergency for preventing cervical tear but pains 
subsided. On 5.5.12 ultrasound revealed low lying placenta reaching upto the os with 22 weeks live intrauterine pregnancy with no congenital malformation, repeat transvaginal cervical cerclage was decided and done in similar manner. She was kept indoor on bed rest, tocolytics, antibiotics and progesterone support till the time of delivery. At 30 weeks pregnancy i.e. on 5.7.12 ultrasound revealed low amniotic fluid index (1.2) for which amino acid infusion was administered. Later on patient developed bleeding \& leaking per vaginum with cervical dilatation on 10.7.12, so decision of immediate cesarean section was taken and corticosteroid administered for fetal lung maturity, emergency cesarean section was done on same day and patient delivered an alive baby. In follow up mother and baby were absolutely healthy.

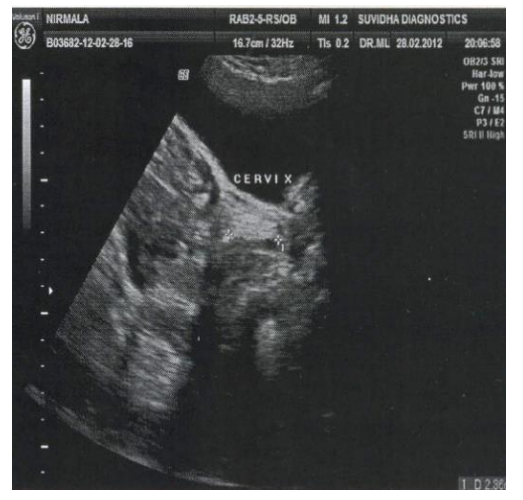

Figure 1: Ultrasound showing incompetent cervix.

\section{DISCUSSION}

Second-trimester abortions are due to maternal illness such as syphilis, hypertension, diabetes mellitus etc or due to a congenital malformation of the uterus, others are caused by "cervical incompetence or insufficiency". The diagnosis is not easy and usually made from the history and sometimes the physical examinations. ${ }^{3}$ Cervical incompetence and infection have been regarded as a major cause of preterm birth which is the leading cause of neonatal morbidity and mortality. Women at high risk of preterm delivery due to cervical incompetence should therefore be followed-up with transvaginal measurements of cervical length. Although $1-9 \%$ of women will experience preterm labor pain after encerclage, risk of chorioamnionitis is $1-7 \%$ and may increase upto $30 \%$ but despite this cervical encerclage is a wonder entity in cases of cervical incompetence leading to recurrent miscarriages.

\section{REFERENCES}

1. Singh G, Sidhu K. Bad obstetric history: a prospective study. Medical Journal Armed Forces India 2010;66(2):117-20.

2. Marliyya Zayyan, Sanusi R. Suhyb, Nwaorga O’C Laurel. The Use of Total Cervical Occlusion along with McDonald Cerclage in Patients with Recurrent Miscarriage or Preterm Deliveries. Oman Med J. 2012 January; 27(1):63-65.

3. Hembah-Hilekaan SK. The Double Monofilament Stitch Still Relevant In Cervical Cerclage: A Report From Makurdi, Nigeria. The Internet Journal of Gynecology and Obstetrics. 2011;15(2). DOI: $10.5580 / 1075$.

DOI: $10.5455 / 2320-1770 . i j r \operatorname{cog} 20131254$

Cite this article as: Sharma N, Ram K, Sharma A.

A unique case report having twice cervical cerclage in same pregnancy with successful fetal outcome in a bad obstetric history patient. Int J Reprod Contracept Obstet Gynecol 2013;2:728-9. 